\title{
PENGONTROLAN KEAMANAN GEDUNG MENGGUNAKAN SINYAL ULTRASONIK YANG DIINTERFACEKAN KE KOMPUTER
}

\author{
Oleh: \\ Muhammad Faisal \\ Universitas Islam Negeri Malang
}

\section{ABSTRAKS}

Piranti komputer mampu untuk mendeteksi adanya pencuri yang memasuki area pintu masuk perusahaan. Selama ini peralatan tersebut sangat mahal apalagi yang memakai kamera. Banyak perusahaan hanya mengandalkan satpam tanpa ditunjang oleh teknologi komputer. Padahal dengan alat ini maka satpam akan sangat mudah untuk mendeteksi adanya pencuri yang masuk ke dalam area perusahaan.

Untuk memenuhi kebutuhan pengamanan maka perlu direkayasa peralatan bantu yang bisa mendeteksi adanya pencuri.

Kata Kunci : Sinyal Ultasonik, Interface

\section{PENDAHULUAN}

\subsection{Latar Belakang}

Teknologi komputer dewasa ini berkembang sangat pesat. Perkembangannya melebar ke berbagai bidang terutama bidang keamanan. Bidang ini termasuk sangat penting bagi ketenangan pengusaha. Pengamanan aset perusahaan perlu adanya bantuan teknologi komputer.

Piranti komputer mampu untuk mendeteksi adanya pencuri yang memasuki area pintu masuk perusahaan. Selama ini peralatan tersebut sangat mahal apalagi yang memakai kamera. Banyak perusahaan hanya mengandalkan satpam tanpa ditunjang oleh teknologi komputer. Padahal dengan alat ini maka satpam akan sangat mudah untuk mendeteksi adanya pencuri yang masuk ke dalam area perusahaan.

Untuk memenuhi kebutuhan pengamanan maka perlu direkayasa peralatan bantu yang bisa mendeteksi adanya pencuri.

\subsection{Rumusan masalah}

Berdasarkan latar belakang penelitian yang telah dikemukakan di atas dapat dirumuskan permasalahan sebagai berikut :

1. Apa yang dimaksud untuk mengontrol keamanan gedung.

2. Bagaimana Implementasi Alat kontrol tersebut.

3. Apa manfaat dari Alat Kontrol tersebut.

\subsection{Tujuan}

Dalam penulisan laporan ini penyusun merencanakan dan membuat sistem pengontrolan peralatan yang bertujuan :

Pembuatan alat untuk mengontrol keamanan gedung dengan menggunakan sinyal ultrasonik. 


\section{TINJAUAN PUSTAKA}

\subsection{Sistem Kontrol}

Sistem kontrol merupakan sistem / cara untuk pengendalian suatu peralatan atau benda yang menjadi target obyek.

Bila ditinjau dari hubungan timbal baiknya dibedakan menjadi 2 :

1. Sistem Loop terbuka

Proses pengendalian dengan tanpa adanya hubungan timbak balik (feetback)

2. Sistem loop tertutup

Proses pengendalian dangan adanya feetback dari alat yang dikendalikan.

Sistem kendali balikan pengontrol akan mengetahui keadaan obyek karena adanya sinyal balik dari obyek mengenai tindakan yang dilakukan.

Dalam sistem kendali dikelompokkan :

1. Menurut metode analisis dan perancangan :

Sistem linear model karakteristik linear

2. Non linear: adanya efek yang mempengaruhi linearitas.

Varian waktu : sistem pengendalian yang berubah menurut waktu yang diinginkan.

2. Invarian waktu : Sistem kendali yang tidak berubah terhadap waktu selama proses operasi.

Menurut bentuk linearitas sinyal yang digunakan :

1. Sistem data kontinyu.

Bentuk sinyal linear / lurus dan stabil tanpa adanya perubahan.

2. Sistem data diskrit.

Bentuk sinyal data berupa bentuk diskrit, selalu berubah dan tidak beraturan.

Sistem kendali data diskrit dibagi :

1. Sistem kendali data cuplik . sistem kendali dengan adanya pembanding/komparator.

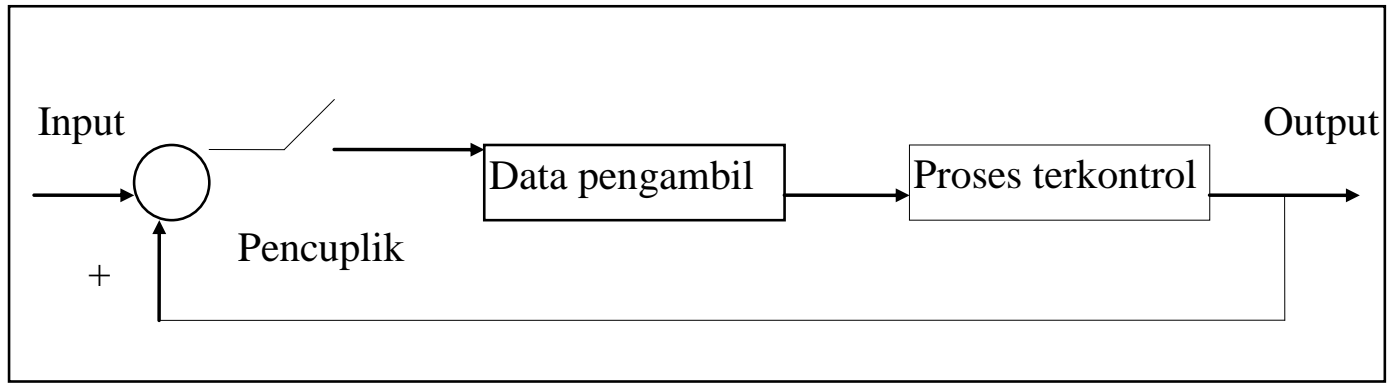

Gambar 2.1. Diagram blok Sistem kendali data cuplik

Gambaran proses sistem kendali data cuplik :

Pada awal proses ada berupa input. Input direspon oleh pembanding kemudian disampling ke data pengambil, data pengambil meneruskan ke proses terkontrol . Bila terjadi error akan ada feetback dan bila sudah tepat akan diteruskan ke output.

\section{Sistem kendali Digital.}

Merupakan Sistem kendali secara digital.

Sistem ini sudah sedemikian populernya karena sangat bagus kualitasnya dibanding analog.

Adapun model sistem kendali digital sebagai berikut : 


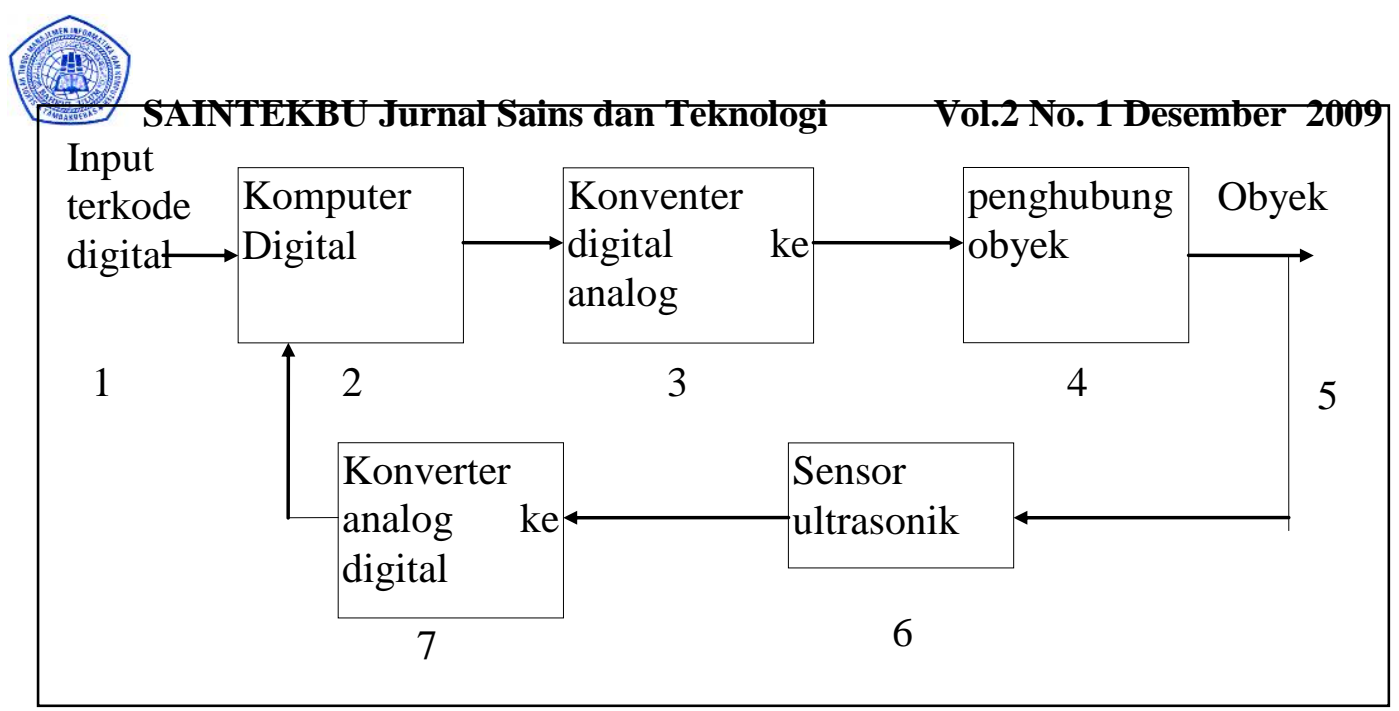

Gambar 2.2. Diagram Blok Sistem Kendali data Digital

\subsection{Sinyal Ultrasonik}

Sinyal ultrasonik merupakan sinyal yang bekerja berdasar prinsip pantulan gelombang suara dan Frekuensi ini bekerja pada Frekuensi $40 \mathrm{KHz}$ hingga sampai frequensi $400 \mathrm{KHz}$. Digunakan untuk mendeteksi keberadaan suatu benda / obyek tertentu di depannya

Sinyal ultrasonik terdiri dari dua unit yaitu pemancar dan penerima. Struktur unit pemancar dan unit penerima ultrasonik

Prinsip kerja dari Sensor Ultrasonik :

1. Sebuah kristal piezoelectric dijepit oleh dua plat logam, sebuah plat di hubungkan dengan mekanik jangkar dan lainnya dihubungkan dengan diafragma penggetar.

2. Plat logam diberi tegangan bolak balik yang mempunyai frekuensi $40 \mathrm{KHz}$ sampai dengan frequensi $400 \mathrm{KHz}$

3. Struktur atom dari kristal piezoelectric akan berkontraksi, mengembang atau menyusut terhadap terhadap polaritas tegangan dan ini disebut pizoelectric. Kontraksi yang terjadi diteruskan kediafragma penggetar sehingga terjadi gelombang ultrasonik yang di pancarkan ke udara . Gelombang ultrasonik merambat di udara dan akan di pantulkan jika mengenai suatu obyek tertentu, pantulan gelombang ultrasonik di terima kembali oleh unit penerima. Selanjutnya unit penerima akan menyebabkan diafragma bergetar dan efek piezoelectric kembali bekerja terbalik .

4. Getaran mekanik dari kristal piezoelectric menghasilkan sebuah tegangan bolak balik dengan frekuensi yang sama. Besar amplitudo sinyal electric yang dihasilkan unit penerima tergantung dari jauh dekatnya obyek yang dideteksi.

\subsection{Penerapan Sinyal Ultrasonik}

Aplikasi dari sensor ultrasonik banyak di gunakan di industri - industri, seperti industri kimia gunanya untuk mengetahui volume atau level dari suatu tangki cairan kimia, dibidang kedokteran dengan ultrasonografi.

Semua aplikasi tersebut bekerja berdasarkan pengukuran waktu untuk mengetahui berat suatu material.

\section{PERENCANAAN DAN PEMBUATAN ALAT}

\subsection{Perencanaan perangkat keras ( hardware ) terlihat pada blok berikut :}




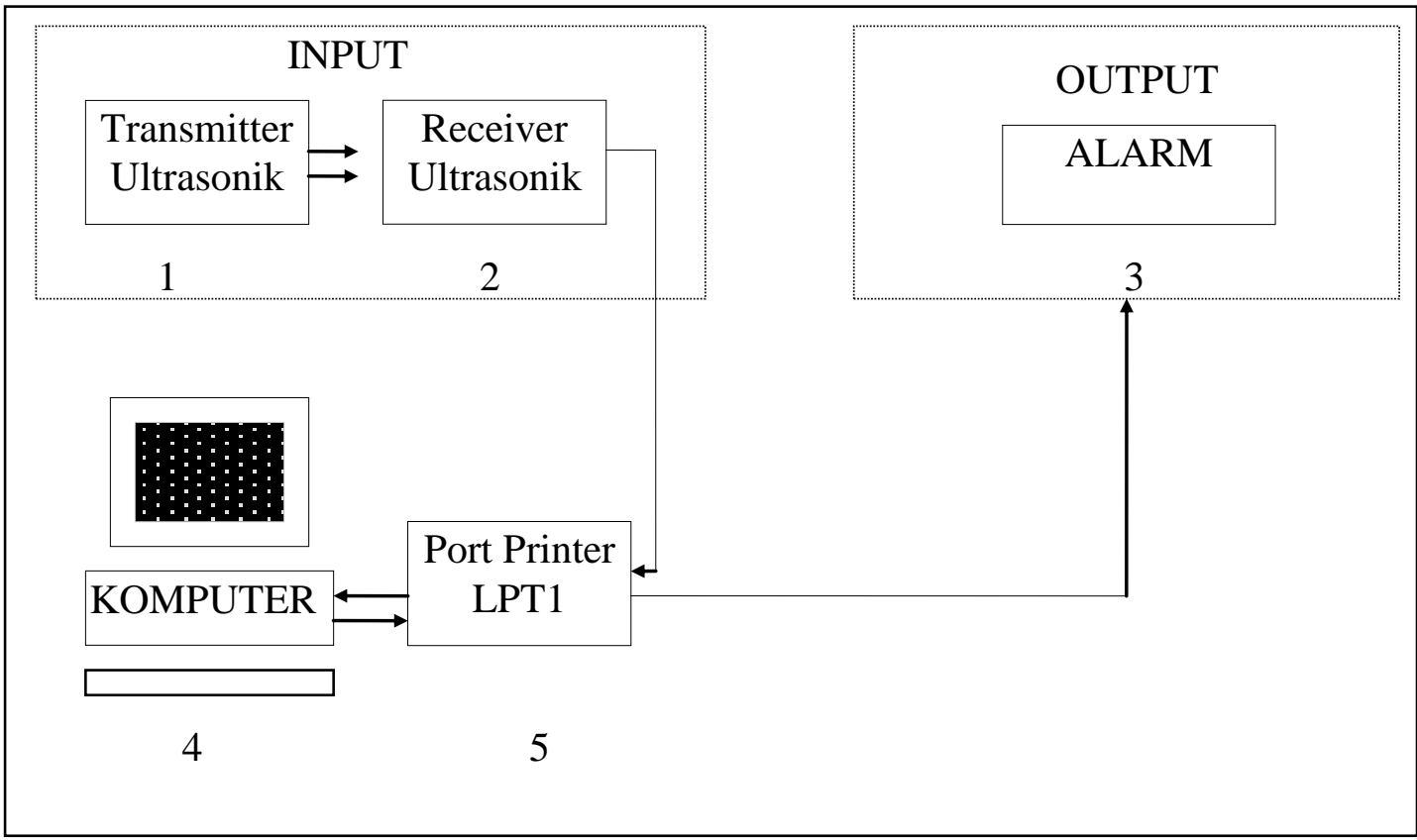

Gambar 3.1. Blok diagram perangkat keras

\subsection{Cara Kerja Sistem}

Peralatan ini terdiri dari 6 bagian pokok, dengan Processor intel 486 DX 33 sebagai pengendali utama.

1. Transmitter Ultrasonik sebagai pengirim sinyal melalui rangkaian astabil multivibrator IC 555.

2. Receiver sebagai penerima sinyal infra yang diperkuat oleh op-amp /demodulator

3. Port Paralel Printer sebagai interfacing antara komputer dengan peralatan I/O.

4. Alarm sebagai penanda adanya aktifitas yang telah terbaca oleh procesor.

5. Procesor berfungsi sebagai pengolah data dari Peralatan I/O melalu paralel port DB.25 dan mengontrol pengendalian peralatan.

Peralatan ini akan bekerja bila Receiver menangkap pantulan gelombang yang dipancarkan oleh Transmitter. Gelombang terpantul karena ada benda sebagai pemantul yang melintas di depan peralatan sensor. Benda ini yang diasumsikan sebagai Pencuri.

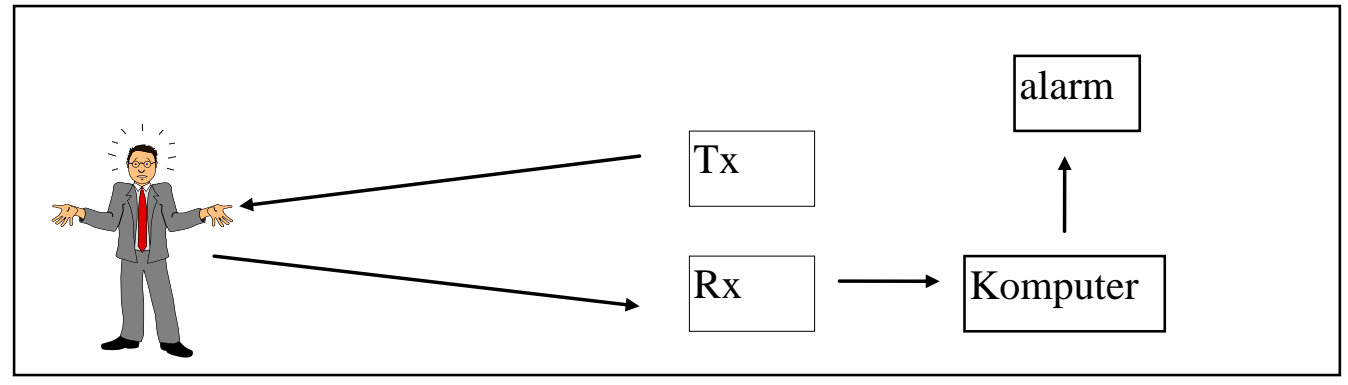

Gambar 3.2. Blok arah sinyal ultrasonik

Tx $=$ Transmitter

$\mathrm{Rx}=$ Receiver

Sinyal dari Tx mengenai Pencuri dipantulkan ke Rx, sinyal tersebut diolah oleh komputer dan akhirnya komputer memerintahkan alarm untuk berbunyi. 
Model Ruangan yang dikontrol :

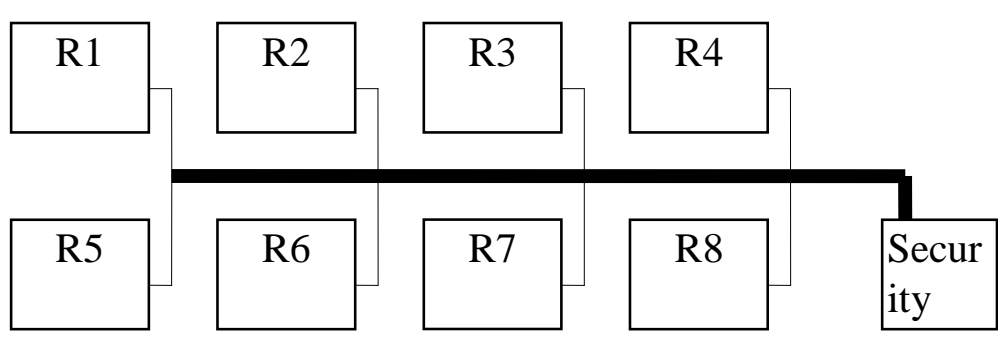

Gambar 3.3. Permodelan ruang yang dikontrol

\subsection{Perencanaan dan pembuatan perangkat lunak.}

Untuk menghubungkan komputer dengan peralatan sensor Ultrasonik maka perlu driver berupa program. Adapun program yang digunakan adalah berbasis Program Pascal 7.0. Adapun pseudo-op algoritma program adalah sebagai berikut :

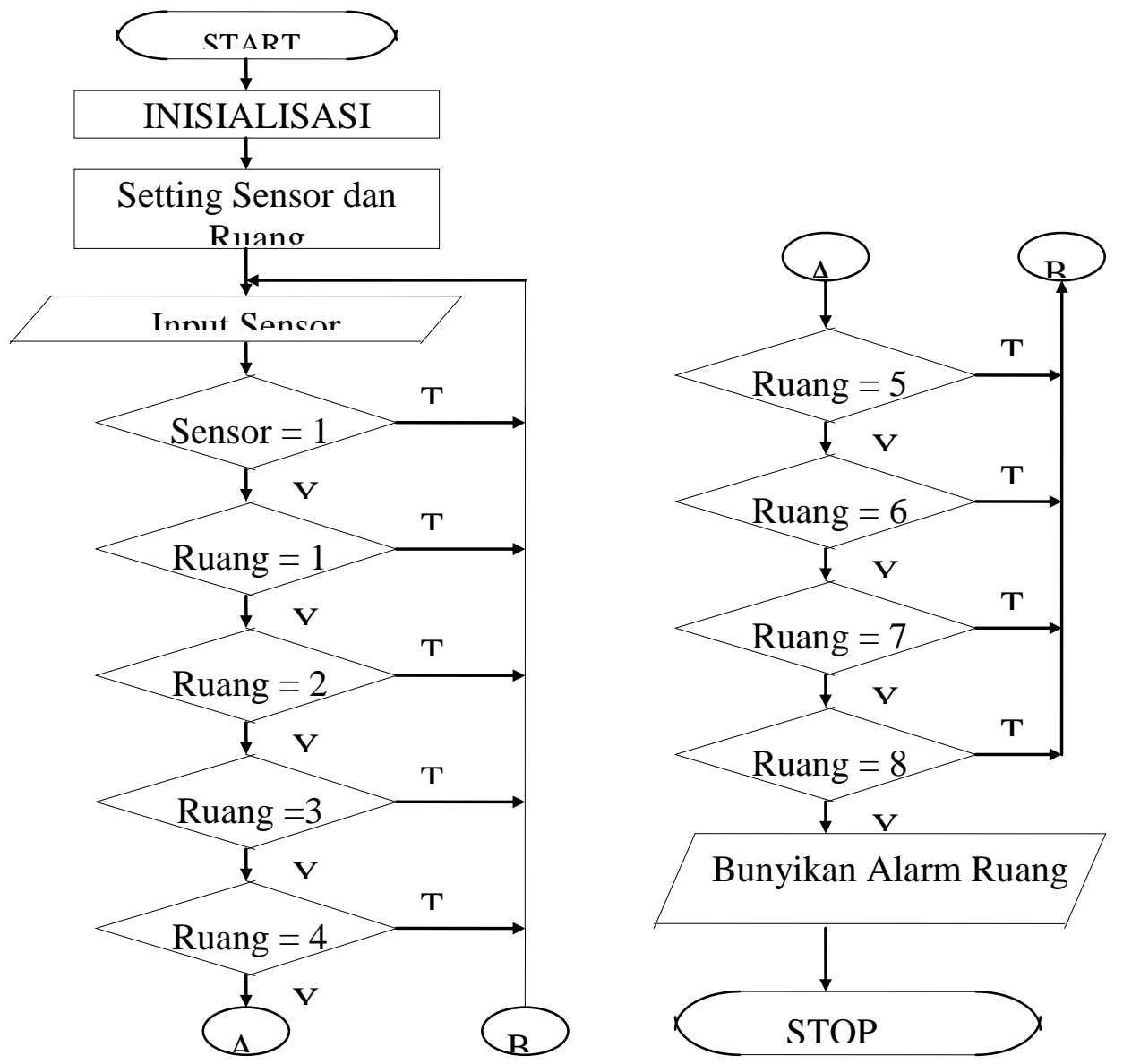

Gambar 3.6. Flow chart program deteksi keamanan Gedung

Program yang dibuat berbasis Pascal yang terdiri dari :

1. Program Unit : Unit Dos, Crt, graph, Layar1

Untuk Unit Dos dan Crt sudah ada dalam fasilitas program TPU (Turbo Pascal Unit) sedangkan Unit Layar1 dibuat tersendiri, karena tidak ada dalam program TPU pada Pascal 7.0.

Contoh model : 
Uses Crt, Dos, graph, layarl ;

2. Procedure terdiri dari :

a. Procedure Bunyialarm

Procedure ini berfungsi untuk membunyikan alarm bila ada ruang yang terdeteksi.

b. Procedure Tampiljudul.

Procedure ini berfungsi untuk menampilkan program tampilan awal sebelum sub program Tampilruang.

c. Procedure Tampilruang.

Procedure ini berfungsi untuk menampilkan ruangan aktif yang akan dideteksi. Ruangan yang direncanakan aktif 1 buah ruangan dari 8 ruangan yang menjadi target.

3. Function :

Function Detekorang.

Function ini sebagai nadi utama pendeteksi adanya orang yang akan masuk ke ruangan.

4. Program Utama.

Program ini menjadi induk dari sub sub program dan menggerakkan semua procedure sesuai dengan perintahnya. Diawali dengan Begin dan diakhiri dengan End.

Perencanaan dan pembuatan model :

Uses crt, Dos, Graph,layar1;

Procedure Bunyialarm;

Function Detekorang;

Procedure Tampiljudul;

Procedure Tampilruang;

Begin

Tampiljudul;

Tampilruang;

End.

\section{PEMBAHASAN}

\subsection{Pengujian Alat}

Peralatan ini terdiri dari sub sistem dan dalam pengujiannya setiap sistem harus saling berkolerasi.

Pengujian Sub sistem :

1. Pengujian subsistem Pemancar : 
Pada pengujian ini input power dihubungkan dengan power adaftor dengan tegangan Vcc 9 V DC. Hasil Output berupa Sinyal Ultrasonik dengan jangkauan frekwensi keluaran dari Timer 555 sebesar $40 \mathrm{KH}$.

2. Pengujian subsistem Penerima :

Pada Pengujian ini input power VCC 9 V DC dengan asumsi masukan untuk beberapa komponen sehingga komponen Ultrasonik bisa memenuhi tegangan DC yang diiginkan sebesar $5 \mathrm{~V}$ DC. Output dari tegangan ini berupa sinyal yang dilinearkan dengan IC. Setelah melewati opamp dan dilinearkan akan menghasilkan tegangan yang dibutuhkan oleh komputer berupa tegangan Digital.

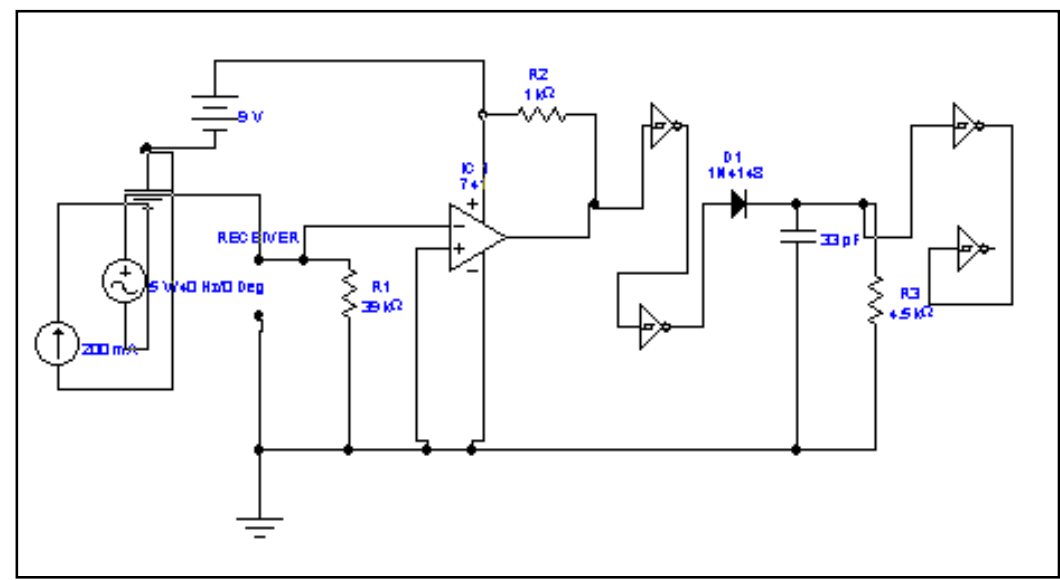

Gambar 4.5. Pengujian sub sistem penerima

3. Pengujian Jarak deteksi

Pengukuran jarak dilakukan dengan mengukur waktu yang diperlukan bagi sinyal yang dipancarkan oleh unit Transmitter dan diterima oleh unit Receiver. Cepat rambat cahaya $340 \mathrm{~m} / \mathrm{det}$.

Proses Pengukuran jarak :

Set komputer pada Port \$379. Sinyal menjangkau benda yang dideteksi (Jangkauan dalam pengujian dalam jarak $\pm 5 \mathrm{~cm}$ ) maka akan terbaca oleh komputer mengakibatkan suara alarm berbunyi dan secara otomatis program akan menampilkan ruangan yang telah terdeteksi oleh sensor tersebut.

4. Tampilan Program :

Tampilan program terlihat sebagai berikut:

a. Tampilan Pertama Program

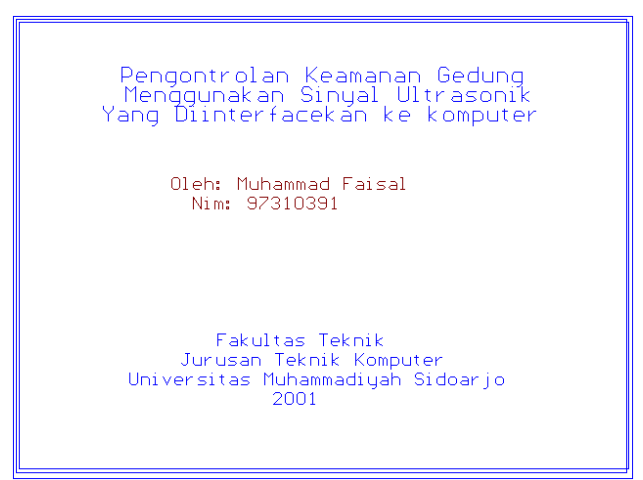


b. Tampilan kedua Program

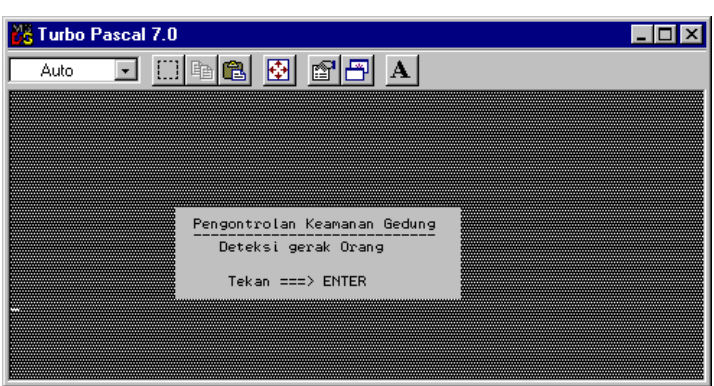

c. Tampilan Ruangan yang terdeteksi Sinyal

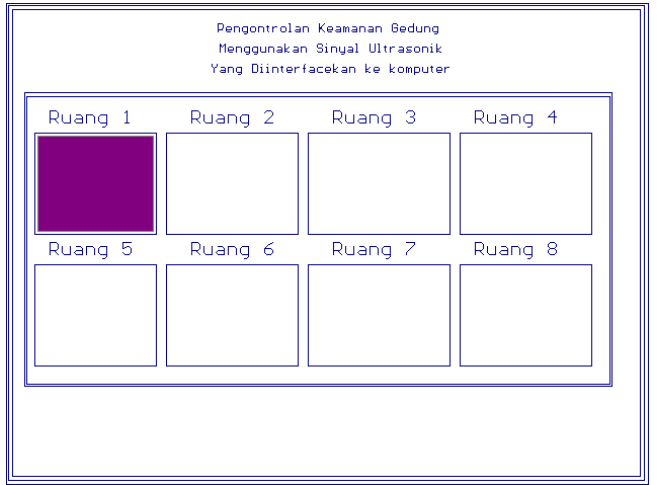

KESIMPULAN

Dari penelitian yang telah dilaksanakan dengan diwujudkan perancangan dan pembuatan alat pendeteksi maka dapat disimpulkan hal sebagai berikut :

1. Pendeteksian benda dapat dilakukan, karena penangkapan benda oleh sensor akibat terpantulnya gelombang ultrasonik.

2. Untuk memperoleh penangkapan sinyal yabg lebih jauh perlu penguatan yang lebih dari pemancar dan penguatan yang lebih pula pada penerima.

3. Pola deteksi ini menggunakan sensor Ultrasonik yang sebelumnya memakai infra merah, karena dari segi pengaruh sinar matahari maka Ultrasonik masih merupakan yang lebih baik dari infra merah sesuai uji lab yang telah dilakukan.

\section{DAFTAR PUSTAKA}

1. Arianto Widyatmo, (1996) Haryanto Eduard \& Fendy, Belajar MikroprosesorMikrokontroller melalui Komputer PC, PT. Elexmedia Komputindo, Jakarta.

2. Charles L. Phillips, Royce D. Harbor, (1996) Sistem Kontrol Lanjutan, Prentice Hall Inc.

3. Douglass V., Microprocessors and Interfacing (1991): Programming Hardware, McGraw-Hill, Inc, United States.

4. Elektuur B.V., (1995) Data Praktis Elektronika, PT. Elexmedia Komputindo, Jakarta.

5. Elektuur B.V. Beek, (1996).Teknik Digit 1 dan 2 , PT. Elexmedia Komputindo, Jakarta. 
6. Insap Santosai, Ir, (1993). Dasar-Dasar Pemrograman Pasccal, Andi Offset, Yogyakarta

7. Malvino Hanapi Gunawan, (1981). Prinsip Prinsip Elektronik, Erlangga, Agustus, Jakarta

8. National semikonductor Corporation, National Operational Amplifiers Databook, Santa Clara, California, 1995.

9. Rizal Rizkiawan, (1997). Tutorial Perancangan Hardware 2, Elexmedia Komputindo, Jakarta.

10. Rodnay Zakky,(1991). Dari Chip ke Sistem : Pengantar Mikroprosessor, Erlangga, Jakarta.

11. Roger L. Tokheim, (1995). Elektronika Digital, Erlangga.

12. Stephen O'Brien and Steven Nameroff, (1993). Turbo Pascal 7 : The Complete Reference, McGraw-Hill,Inc, California-USA.

13. Suyanto EA,(1992). Cara Mudah Belajar Assembley, Semarang, 1992.

14. Wasito S., (1992). Data Sheet Book1 : Data IC Linear, TTl dan CMOS, PT. Elexmedia Komputindo, Jakarta. 